\title{
The Epistemic Value of Open Science
}

\author{
Siraprapa Chavanayarn ${ }^{1} *$ \\ ${ }^{1}$ Chulalongkorn University, Thailand
}

\section{OPEN ACCESS}

Citation: Chavanayarn S. (2018)

The Epistemic Value of Open

Science. Open Science Journal 3(2)

Received: $4^{\text {th }}$ April 2018

Accepted: $16^{\text {th }}$ June 2018

Published: $1^{\text {st }}$ July 2018

Copyright:@ 2018 This is an open access article under the terms of the Creative Commons

Attribution License, which permits unrestricted use, distribution, and reproduction in any medium, provided the original author and source are credited.

Funding: Ratchadaphiseksomphot Endowment Fund of

Chulalongkorn Univeristy

Competing Interests: The author has declared that no competing interest exists.
*Corresponding author: Siraprapa Chavanayarn: siraprapa.c@chula.ac.th

Keywords: Open Science, Open Collaborative Science, Citizen Science, Epistemic Value

\section{Introduction}

Open science refers to all scientific culture that is described by its openness. It may often include features of open access, open data, and open source. Fecher and Friesike (2014) identify five open science schools of thought: the public school, which is about the accessibility of knowledge creation; the democratic school, which is about equality of access to knowledge; the pragmatic school, 
which is about collaborative research; the infrastructure school, which is about the technological architecture, and the measurement school, which is about alternative impact measurement.

This article argues that there are only two open science schools, the public and democratic iterations that can defend themselves against the serious epistemic objections to open science. In addition, if society supports an "open discussion" policy, both scientists and citizens will gain much more benefit from open science.

The article is divided into three sections. The first section will briefly explain open science's feature and schools of thought. The next section will engage in the debates about serious epistemic objections to open science and will propose that some schools of thought can defend themselves against such objections. The final section will propose that if society supports an "open discussion" policy, both scientists and citizens will gain much more benefit from open science.

\section{Open science's feature sand schools of thought}

As I mentioned earlier, open science may often include features of open access, open data, and the open source. By "open access," I mean it is free on the internet, permitting users to read, download, copy, distribute, print, search, or link to the full texts of these articles. Some open science theorists such as Peter Kraker (2011) state that open science means opening up the research procedure by making all its outcomes openly accessible on the World Wide Web. By "open data," I mean publishing the datasets collected in the research process on the World Wide Web without restricting their use (Murray-Rust, 2008: 52). Finally, by "open source," I mean software that is made available under a license that permits anyone to use, change, improve, or derive from existing source code, and sometimes even to distribute the software (Feller and Fitzgerald, 2002: 646).

As I have mentioned, Fecher and Friesike (2014) identify five open science schools of thought: the public school, which is about the accessibility of knowledge creation; the democratic school, which is about equality in accessing knowledge; the pragmatic school, which is about collaborative research; the infrastructure school, which is about technological architecture; and the measurement school, which is about alternative impact measurement. Fecher and Friesike look at the literature on open science and identify its schools of thought by referring to the difference of aims and assumptions about open science. But they do not make a clear-cut distinction between these schools. They just want to give a comprehensible overview of the predominant thought patterns in the current open science discourse. I will briefly describe the five schools of thought Fecher and Friesike propose for basic information for discussion.

\section{(1) The public school}

According to the public school, science needs to be accessible to the public. Advocates of the public school usually claim that Web 2.0 technologies allow scientists to open up the research process and arrange the product of their research for interested non-experts. (Fecher and Friesike, 2014: 19) Fecher and Friesike recognize two different streams within the public school.The first is 
concerned with the accessibility of the research process, while the second is associated with the comprehensibility of the research result. Both streams include the relationship between scientists and the public and describe openness as dedication to a wider audience. Morris and Mietchen (2010), for example, maintain that Web 2.0 can make knowledge production accessible for the public. In this regard, Cribb and Sari demand a change in the scientific writing style: "Science is by nature complicated, making it all the more important that good science writing should be simple, clean and clear" (Cribb and Sari: 2010, 15).

\section{(2)}

\section{The democratic school}

An assumption of the democratic school is equality of access to knowledge. According to the democratic school, knowledge should be equally distributed. Unlike the public school, which promotes accessibility in terms of participation inresearch and its comprehensibility, advocates of the democratic school focus on the principal access to the products of research (Fecher and Friesike, 2014: 25). Cribb and Sari, for example, make the case for open access to scientific knowledge as a human right. They contend there is a gap between the creation and the sharing of knowledge. While scientific knowledge doubles every 5 years, access to this knowledge remains limited (Cribb and Sari, 2010: 3). Phelps regards open access to research publications as a catalyst for development, whereas limited access to a small subset of people with subscriptions is a hindrance to development. He argues that research funded by taxpayers should be made available to the public free of charge so that the taxpayer does not in effect pay twice for the research (Phelps, 2012: 1).

\section{(3) The pragmatic school}

According to the concept of this school, knowledge creation would be more efficient if scientists worked together. Its central aim is to open up the process of knowledge creation to make research and knowledge dissemination more efficient (Fecher and Friesike, 2014: 32)/Advocates of the pragmatic school argue that science can be optimized in many ways, for instance, by allowing collaboration through online tools. Gowers and Nielsen (2009) argue that natural sciences can profit from researchers' collaboration. Tacke (2010) proposes that complex situations can be better judged by the collective wisdom of the crowds.

\section{(4) The infrastructure school}

The basis of infrastructure school is that efficient research depends on the available tools and applications. Its central aim is to create openly available platforms, tools and services for scientists (Fecher and Friesike, 2014: 36). Foster (2003) claims that science is as much based on computation, data analysis, and collaboration as on the efforts of individual experimentalists and theorists, driven by increasingly complex problems and by advances in understanding and technique, and powered by the emergence of the Internet.

\section{The measurement school}

The measurement school posits that scientific contributions need alternative impact measurements. Evidently, the impact factor, which measures the number of citations in a journal, influences a researcher's reputation and his or her job 
opportunities. It is therefore hardly surprising that a discussion about open science is accompanied by the essential problem of how scientific impact can be measured in the digital age. For that reason, this school makes the case for an alternative and faster impact measurement that includes other forms of publications (Fecher and Friesike, 2014: 40). Priem and Light Costello (2010) argue that Twitter posts, which are much faster than traditional citations, can be used to measure scientific impact.

Open collaborative science projects closely connect with open science because they embrace the concepts of open science: open access, open data, and open source. Examples of open collaborative science projects is the Polymath Project (in which Tim Gower posted a mathematical problem on his blog that was then solved by a few experts), the Galaxy Zoo Project (an online astronomy project that amateurs can join to assist morphological classification) and the eBird Project (an online project that citizens can join to report bird observations).

\section{Epistemic objections to open science}

In this section, I will discuss serious epistemic objections to open science and will propose that particular schools of thought, the public and democratic schools, can effectively defend themselves from such objections or have fewer epistemic problems than the other schools. By "epistemic objection," I mean an objection that is about beliefs or a justification for a belief. Therefore, an argument that rejects open science due to the concept of copyright is not an "epistemic" objection to open science, but an argument that rejects open science because "open science can make citizens generate a false belief" is an epistemic objection.

First, Neilsen (2012) explains that an objection is an epistemic objection to open science. Specifically, some might claim that the public will misunderstand science information because of open science. That is, because most scientific knowledge are complex, open science that openly reveals scientific knowledge to the public may make some people, especially those who do not have enough basic scientific knowledge, misunderstand science. He maintains that NASA's case in 2009 shows that the scientific society worries about citizens' misunderstanding scientific information. In 2009, NASA launched the Kepler spacecraft and announced that they would release collected data in June 2010. Later, they decided to postpone release so their scientists could look at it first. Their rationale was that non-scientists might unintentionally misapprehend the data, and NASA scientists thought it would be preferable for them to be familiar with the data in advance so that they could report on it (Nielsen, 2012: 201).

In response, I grant that this epistemic objection can attack some open science schools of thought. I actually agree that if scientists reveal their research in the same way as they write in academic journals, the public may definitely misunderstand the information. However, I do not think that this situation is a serious epistemic objection to all open science schools of thought. The basic assumption of the public and democratic schools is about the accessibility of knowledge, so its proponents work to make the public understand the complexity of scientific knowledge since they want to make science accessible for all levels of 
citizens. Many books explain how scientists can communicate to the public. Open Science: Sharing Knowledge in the Global Century (2010) argues that "Science is by its nature complicated, making it all the more important that good science writing should be simple, clean and clear" (Cribb and Sari, 2010: 15). The book claims that scientists need to reflect on the audience since this is the first step in writing well. Specifically, they should think about who the audience is, what they want from the science, and what their level of technical understanding is. This book convinces scientists that simplicity is strength and is a good foundation for communication. The audience can easily understand the complex ideas of scientific knowledge if the language is simple and clear. This book also directs scientists to use short sentences and use language their audience uses habitually. A good science article often goes directly to the meaning of the science to society, rather than to the science itself. According to these two schools, open science should not focus on the collaboration without realizing the importance of communication with the public. If we know that open science can cause citizens who do not have much basic knowledge about science to misunderstand scientific information, we should find a way to make them understand scientific information better instead of rejecting open science.

In sum, it seems that the public and democratic schools of thought have already recognized the problem of misunderstanding, and since their central aim is citizens' accessibility to scientific knowledge, advocates of these two schools try hard to make citizens correctly and equally understand scientific knowledge. Unlike the other schools of thought that aim only at scientific societies, citizens are involved as a part of science in these two schools of thought. Therefore, the public and democratic schools of thought that focus not only on the advantage of scientific societies but also the advantage of citizens have more epistemic value than any other schools and also can refute this objection to open science.

Another epistemic objection to open science is about the methodology of open collaborative science projects. That is, it seems that open collaborative science projects focus on collaborative research between scientists and novices. Many collaborative open science projects invite the public to help scientists. This shows that the open science projects require collective knowledge that is collaboratively generated from the group. "Groupthink," which causes members of the group to unquestioningly follow the word of the leader, can occur in the process of generating knowledge. Groupthink, a term coined by social psychologist Irving Janis (1972), occurs when a group makes defective decisions because group pressures lead to a deterioration of mental efficiency, reality testing, and moral judgment. Groups affected by groupthink ignore alternatives and tend to take irrational actions that dehumanize other groups. A group is especially vulnerable to groupthink when its members are similar in background, when the group is insulated from outside opinions, and when there are no clear rules for decisionmaking. Therefore, groupthink implies a negative picture for collective intelligence. It indicates that groups often do not do a good job of taking advantage of their collective knowledge.

However, Nielsen (2012) argues that science is well suited for collective intelligence. Most fields of science have a large repository of powerful techniques shared by the scientists working in that field. The discovery of the structure of DNA is an example that demonstrates the strength of the shared praxis in science. I actually agree that groupthink can happen during open collaborative 
science projects, but we should not give up on such projects just because it can happen. What we should do is prevent groupthink from taking place instead of rejecting open science. There are many solutions to protect open science from groupthink. According to Irving Janis, decision-making groups are not necessarily destined to groupthink. He formulated several ways of preventing groupthink. For example, a team should set up several independent groups that work on the same problem, all effective alternatives should be examined, and leaders should assign each member the role of "critical evaluator" (Janis, 1972: 209-15). This allows each member to freely air objections and doubts. Groupthink is not a sufficient epistemic reason to repudiate open science because it can happen or can be avoided in open science projects.

Moreover, the public school aims to make science accessible for all levels of citizens, and the democratic school aims to make knowledge equally accessible for everyone, so both can create an environment that can decrease the groupthink problem. If all levels of citizens possess enough scientific information, they can critically deliberate the information. This situation can encourage diversity of opinion, and diversity can reduce groupthink since there are many ways citizens can think about the issue. As we know, a group is especially vulnerable to groupthink when its members are similar in background and when the group is insulated from outside opinions. If society has diverse opinions, it will be less vulnerable to groupthink. Furthermore, we can now communicate and discuss anything via Web2.0, which is a convenient tool for deliberating and anonymously discussing an issue. Anonymity sometimes causes positive epistemic consequences since it enables us to more freely contribute our epistemic resources and can enhance error detection by enabling increased transformative criticism to weed out error and bias.

In sum, the public and democratic schools of thought can effectively deal with groupthink better than the other schools. The infrastructure school, for instance, which aims to create openly available platforms, tools and services for scientists, does not focus on ways to reduce groupthink.

Nielsen (2012) posits another epistemic argument against open science, contending that open science, which aims to make scientific research, data, and dissemination accessible to all levels of an inquiring society, can be used by those who receive the scientific knowledge to do bad things. For example, in 2011, Dutch researchers declared their intention to publish a research paper describing the formation of a strain of H5N1 influenza that can be simply passed between ferrets, the mammals that most closely mimic the human response to the flu. The announcement generated a debate in both political and scientific circles about the ethical consequences of publishing scientific documents that could be used to build biological weapons. This is one example of how science data could possibly be abused (Nielsen, 2011: 200).

This seems to be a serious objection to both the public and democratic schools of thought. The more scientific information is known, the more opportunities exist for the information to be abused. I accept that data could possibly be abused; however, we should not try to prevent such abuse by rejecting open science. Scientific data could be useful as well as abused. The most evident benefit of widespread open access is to individual citizens. They can simply find scientific information about what they want to know, and this ability can better their lives. For example, when they are ill, there would be no more restrictions on 
their ability to download the latest research. They can find medical information, including discussions about the information. Therefore, rejecting open science because it can possibly be abused may be a hasty decision. This objection only reminds scientists to be careful before giving access to their research to citizens. It seems that some topics should not be revealed to citizens to protect the security of society. But this is not a sufficient reason to limit what open science contributes to society.

To summarize, the public and democratic schools of open science can refute serious epistemic objections better than the other schools. If an objection seems to directly attack these two schools, the objection is not a sufficient reason to reject open science.

\section{Open Discussion policy}

As noted, some schools of open science can protect themselves from serious epistemic objections. Since these schools focus on accessibility and equality of access to knowledge, if any governments support such schools of open science, there will be more communication from scientists to the ordinary citizen. If knowledge is intrinsically valuable, the communication is virtuous and benefits the citizen. However, such communication is one-way because it only motivates scientists to simplify and spread their scientific knowledge to citizens, not vice versa.I propose that societies can take more advantage of these two schools of open science if their governments simultaneously support an open discussion policy. By "open discussion," I mean situations in which citizens can discuss the scientific information without fear of government retaliation or censorship. This policy, plus Web 2.0 technology, will support a fast and real-time multidirectional communication among scientists and citizens.

These communications will benefit both open scientists and citizens. The scientists will gain feedback about their research from many points of view. From this, they can realize what society wants from them and what the real impacts of their research are. In addition to gaining scientific information that may be useful for their daily lives, citizens will learn what other citizens think about the information, so they can reflect upon others' opinion. Open discussion in large groups usually brings diversity of opinions, and diversity can expand the range of possible solutions. This can make citizens more careful before accepting or applying the scientific information. Therefore, societies can take better advantage of these two schools of open science if their governments concurrently support an open discussion policy because the policy supports multidirectional communications among scientists and citizens. Such communication will be a great benefit to both scientists and ordinary citizens.

\section{Conclusion}

In conclusion, the public and democratic school of open science can defend themselves against the serious epistemic objections: misunderstanding and groupthink. Specifically, these two schools have already recognized some 
epistemic objections, especially the problem of misunderstanding scientific information, and are working to help scientists communicate with citizens. Although there is an epistemic argument against these two schools, the argument is not a sufficient reason to reject open science since there are many ways to prevent those objections. If we accept that knowledge is valuable in itself and that all citizens are equal, these two schools of open science do something that has epistemic value, because the aims of these two schools of thought can cause all levels of citizens to have more knowledge. Unlike the other schools of thought that seems to affect only scientific societies, these two schools directly expand the benefits of open science to the levels of an inquiring society, whether novice or professional. Furthermore, if their governments simultaneously support an open discussion policy, societies can take more advantage of the two schools because the policy supports multidirectional communications that will benefit both open scientists and ordinary citizens.

\section{References:}

Cribb, J. and Sari, T. Open science: sharing knowledge in the global century. VIC: CSIRO Publishing; 2010.

Fecher, Benedikt and Friesike, Sascha. Open Science: One Term, Five Schools of Thought. in SönkeBartling and SaschaFriesike, eds. Opening Science: The Evolving Guide on How the Web is Changing Research, Collaboration and Scholarly Publishing. London: Springer; 2014: 17-48.

Feller, J. and Fitzgerald, B. Understanding Open Source Software Development. Addison-Wesley, Boston; 2002.

Foster, I., 2002. The Grid: A New Infrastructure for 21st Century Science. Physics Today 2002; $55(2): 42$.

Gowers, T. and Nielsen, M.. Massively collaborative mathematics. Nature 2009; 461(7266): 879-881.

Janis, I. L. Victims of Groupthink: A Psychological Study of Foreign-Policy Decisions and Fiascoes. Boston: Houghton Mifflin; 1972.

Kraker, Peter et al. The Case For An Open Science in Technology Enhanced Learning. Int. J. Technology Enhanced Learning 2011;3,6: 643-654.

Morris, T. \&Mietchen, D. Collaborative Structuring of Knowledge by Experts and the Public. In Proceedings of the 5th Open Knowledge Conference. (London, UK); 2010. p. 29-41.

Murray-Rust, P. Open data in science. Serials Review2008;34,1:52-64.

Nielsen, M.A. Reinventing discovery: the new era of networked science. N.J.: Princeton University Press; 2012.

Phelps, L., Fox, B.A. and Marincola, F.M. Supporting the advancement of science: open access publishing and the role of mandates. Journal of translational medicine 2012; 10: 13.

Priem, J. and Costello, K.L. How and why scholars cite on Twitter. Proceedings of the American Society for Information Science and Technology; 2010:47(1). p. 1-4.

Tacke, O. Open Science 2.0: How Research and Education Can Benefit from Open Innovation and Web 2.0. In T. J. Bastiaens, U. Baumöl, and B. J. Krämer, eds. On Collective Intelligence. Heidelberg: Springer Berlin Heidelberg 2010; 37-48. 